\title{
Multimodal Analgesic Effect on Proinflammatory and Anti-inflammatory Cytokines Serum
}

\author{
Muhammad Ramli Ahmad, ${ }^{1}$ Tatang Bisri ${ }^{2}$ \\ ${ }^{1}$ Department of Anesthesiology, Intensive Care and Pain Management, Faculty of Medicine, Hassanudin \\ University-Dr. Wahidin Sudirohusodo General Hospital \\ ${ }^{2}$ Departement of Anesthesiology and Intensive Care, Faculty of Medicine Universitas Padjadjaran-Dr. Hasan \\ Sadikin General Hospital
}

\begin{tabular}{|c|c|}
\hline Abstract & $\begin{array}{l}\text { Objective: To investigate the effect of combination epidural bupivacaine and } \\
\text { intravenous parecoxib analgesia on immune response in patients who underwent } \\
\text { open reduction and internal fixation of the lower limb under epidural anesthesia. } \\
\text { Methods: This research was conducted using the randomized, placebo-controlled } \\
\text { double blind trial method on } 52 \text { patients who were randomly divided into } 2 \\
\text { groups: the Parecoxib group which received } 40 \text { mg intravenous parecoxib for } 30 \\
\text { minutes before incision and the control group which received an equal volume of } \\
0.9 \% \text { normal saline. Both groups received epidural anesthesia and postoperative } \\
\text { epidural } 0.125 \% \text { bupivacaine analgesia continously. Venous blood samples were } \\
\text { obtained before parecoxib administration, } 2 \text { and } 24 \text { hours after the surgery. The } \\
\text { data were analyzed using Mann Whitney } U \text { and independent tests }(p<0.05) \text {. }\end{array}$ \\
\hline & $\begin{array}{l}\text { Results: There was a significant difference between the two groups }(p<0.05) \text { in } \\
\text { IL-1 } \beta, \text { IL-6, IL-10 levels and proinflammatory to anti-inflammatory ratio, } 2 \text { hours } \\
\text { after surgery. }\end{array}$ \\
\hline $\begin{array}{l}\text { Received: } \\
\text { September 17, } 2013\end{array}$ & $\begin{array}{l}\text { Conclusions: Multimodal analgesic combination of } 40 \mathrm{mg} \text { IV parecoxib and } \\
0.125 \% \text { bupivacaine epidural analgesia have the effect to alter and stabilize the } \\
\text { systemic immune response. }\end{array}$ \\
\hline $\begin{array}{l}\text { Revised: } \\
\text { January 25, } 2014\end{array}$ & $\begin{array}{l}\text { Keywords: Cytokines, epidural analgesia, interleukins, immune response, } \\
\text { parecoxib, tissue damage }\end{array}$ \\
\hline $\begin{array}{l}\text { Accepted: } \\
\text { April 10, } 2014\end{array}$ & IJIHS. 2014;2(1):15-22 \\
\hline
\end{tabular}

\section{Introduction}

Postoperative pain brings a significant impact on patients. However, the management of the postoperative pain is still occasionally overlooked even though there are recent developments and extensive understandings on postoperative pain mechanism. Almost half of all postoperative patients had not received proper postoperative pain management and about $80 \%$ of them were still in acute pain postoperatively. ${ }^{1}$ Research conducted in Maastricht University Hospital, the Netherlands, showed that about $41 \%$ of 1,490

\footnotetext{
Correspondence:

Muhammad Ramli Ahmad, Department of Anesthesiology, Intensive Care and Pain Management, Faculty of Medicine, Hassanudin University, Dr. Wahidin Sudirohusodo General Hospital

Jl. Perintis Kemerdekaan KM 10, Makassar, Indonesia e-mail: m_ramli_ahmad@yahoo.co.id
}

postoperative patients were still in moderate to severe pain on the $1^{\text {st }}$ to $4^{\text {th }}$ day post-surgery in spite of the standard pain management protocol. About $30-55 \%$ of post abdominal surgery patients were still in moderate to severe pain on the $1^{\text {st }}$ day, about $20-71 \%$ of post lower extremity surgery and $30-64 \%$ of post spinal surgery were still in moderate to severe pain on the $1^{\text {st }}$ to $4^{\text {th }}$ day. ${ }^{2}$

The inflammation responses to postoperative trauma may induce the neuroendocrine stress responses. The inflamed peripheral tissue produces cytokines, i.e. Interleukin-1 $\beta$ (IL- $\beta$ ), IL-2, IL-6 and tumor necrosis factors (TNF). The humoral signal induces the cyclooxygenase 2 (COX-2) activity and, therefore, prostaglandin synthesis in central nervous system (CNS) which leads to sensitization. This cannot be inhibited effectively by regional anesthesia. However, the 
centrally-acting COX-2 inhibitor administration will reduce this activity. ${ }^{3}$ The circulation of the T-helper cell (Th) is associated with cytokine expression. Th1 cell is associated with immune cells, e.g. interferon $\gamma($ INF- $\gamma)$, IL-2 while Th2 produces IL-4, IL-5 and IL-10, which are associated with the immunosupression response. The balance of IL- 6 and IL-10 is an important factor in the series of immune responses. ${ }^{4}$ The COX2 expression is stimulated by proinflammatory cytokine and inhibited by anti-inflammatory mediators, such as IL-10 and IL-4, through transformation growth factor-beta (TGF-beta). ${ }^{5}$

A study on preemptive analgesia by using epidural technique associated with pain score and the cytokine production proved that the use of epidural preemptive could reduce the pain score and production of IL-1 $\beta$, IL-6, IL-1ra. ${ }^{6}$ On the other hand, another research showed that epidural technique could only inhibit the neural line and could not inhibit the humoral line. ${ }^{7}$ The use of rofecoxib combination and spinal anesthesia on pelvic surgical operation showed reduction in IL-6 and prostaglandin E2 (PGE2) levels in cerebrospinal fluid (CSS), plasma, and wound side while TNF $\alpha$ dan IL$1 \beta$ could not be detected both in plasma and CSS. ${ }^{8}$ A study on the effect of a single parecoxib administration on cytokine response, and stress response as well as the administration of ophthalmological postoperative analgesia showed significant decreases in IL-6, IL-8, cortisol adrenocorticotropic, and VAS $(p<0.001)$ compared to the control groups. There were no decreases in epinephrine and norepinephrine levels in both group. ${ }^{9}$

Another study suggested that the use of multimodal analgesia with IV tramadol and IV flurbuprofen combination in thoracotomy postoperative pain management were able to reduce the pain score, IL-6, and postoperative C-reactive protein (CRP) compared to the pain score in the control groups. The TNF- $\alpha$ level was similar for both groups. ${ }^{10}$ Epidural preemptive analgesia showed lower pro-inflammation/antiinflammatory cytokine ratio than the control groups, but the difference was not significant. This proved that epidural preemptive could not reduce central sensitization through the hormonal line. ${ }^{11}$

The effect of centrally-acting multimodal analgesia COX-2 inhibitor combined with epidural analgesia on immune response and pain intensity has not been studied extensively. Hence, in order to improve our understanding, holistic studies are needed to examine the inflammation and anti-inflammatory cytokine level as well as the IL-6/IL-10 ratio in patients receiving $40 \mathrm{mg}$ IV parecoxib and with $0.125 \%$ epidural bupivakain analgesic combination.

\section{Methods}

This study was conducted in Dr. Wahidin Sudirohusodo General Hospital, Makassar from April to July 2012 and was approved by the Ethics Committee of Hasanuddin University Makassar. All patients who met the inclusion criteria were consecutively enrolled. This study was performed using the clinical double-blind randomized case-control study design.

Male patients who underwent open reduction internal fixation elective surgical operation of lower hip fracture with epidural anesthesia and who met the following inclusion criteria, i.e. PS ASA $1-2,18-50$ years of age, height more than $155 \mathrm{~cm}$ and normal $\mathrm{BMI}$, were included in this

Table 1 Demographic Characteristics of Patients

\begin{tabular}{|c|c|c|c|c|c|}
\hline \multirow{3}{*}{ Variable } & \multicolumn{4}{|c|}{ Group } & \multirow{3}{*}{ p value*) } \\
\hline & \multicolumn{2}{|c|}{ Parecoxib $(n=26)$} & \multicolumn{2}{|c|}{ Control (n=26) } & \\
\hline & Range & Mean $\pm S D$ & Range & Mean \pm SD & \\
\hline Age & $23-50$ & $35.96 \pm 10.25$ & $18-48$ & $29.15 \pm 9.43$ & 0.61 \\
\hline Height & 157-174 & $16.8 \pm 4.43$ & $154-173$ & $165.15 \pm 5.51$ & 0.53 \\
\hline BMI & $20.20-24.38$ & $21.93 \pm 1.38$ & $20,01-24,80$ & $21.18 \pm 1.36$ & 0.36 \\
\hline Duration of operation & $100-175$ & $141.73 \pm 20.73$ & $100-175$ & $139.61 \pm 25.33$ & 0.57 \\
\hline Consumption of local anesthesia & $90-135$ & $110.76 \pm 22.87$ & $90-135$ & $110.76 \pm 22.87$ & 0.57 \\
\hline PS ASA & $1-2$ & 1.00 & $1-2$ & 1.00 & 0.81 \\
\hline
\end{tabular}


study. Patients who had contraindications for epidural catheter placement, history of allergy to study medicines, cardiovascular disease, renal failure, liver damage, signs of SIRS, under NSAID less than 5 days before the procedure, and under corticosteroid were excluded. Patients who experienced intraoperative complications, needed resurgery during observation period, needed blood transfusion, had non-optimal epidural anesthesia, and underwent more than 3-hour operative procedure were also excluded. Samples were obtained using consecutive random method. Fifty two patients were enrolled and divided into 2 groups, which was parecoxib group and control group.

Patients were given $5 \mathrm{mg}$ alprazolam prior to the operation as the inclusion criteria met. Epidural catheter insertion at the level of of $L 2-3$ or L3-4 was done at the operation room. Fourty milligrams intavenous Parecoxib was given to the parecoxib group about 30 minutes prior to incision, while the control group were given 2 cc $0.9 \% \mathrm{NaCL}$. Bupivakain epidural anesthesia, $0.5 \% 1-2 \mathrm{~mL} /$ dermatome, was administered 30 minutes prior to the incision until the block reached T12-S2. During the procedure, patients were sedated with $25-100 \mu \mathrm{g} / \mathrm{kg} /$ minute IV propofol. After the procedure, both groups were given continuous $0.125 \%$ bupivacaine, $5 \mathrm{cc} / \mathrm{hour}$, as the post-operative analgesia. Blood samples was taken 2 and 24 hours after the procedure and the IL-1 $\beta$ and IL- 6 serum levels were measured. The pain intensity was assessed using Numeric Rating Score (NRS) and $3 \mathrm{~mL}$ of $0.125 \%$ bupivacaine was given when the NRS was more than 4/10. The Human Interleukin Immunoassay Quantikine HS serum ( $\&$ \& D System) was used to measure the cytokine level using the Enzyme Linked Immunosorbent Assay with ELISA Reader Organon 680 (Biorad) equipment.

The collected data were then processed with SPSS 15.0 software for Windows. Data were examined using $t$ test for characteristics of samples. The differences of variables between both groups were examined using MannWhitney U-test. The number of samples needed in each group were $26(\alpha=0.05$ and power $=0.8)$. Differential test between variables in both groups was considered significant if $p<0.05$. Data are presented in mean $\pm S D$ and minimummaximum/median.

\section{Results}

Demographic characteristics of both groups in age, height, body mass index, duration of operation, consumption of local anesthesia and ASA between the two group, therefore the two group were considered homogenous (Table 1 ).

The difference of IL-1 $\beta$ level between the parecoxib group and the control group was not statistically significant $(p>0.05)$, both in preoperation and 24 hours post-operation levels. At two hours after the surgery, the IL- $1 \beta$ level in parecoxib group was significantly different $(p<0.05)$ from the control group (Fig. 1).

The IL- 6 average value in parecoxib group and control group was not significantly different in pre-operation $(p>0.05)$ and 24 hours postoperation $(p>0.05)$. However, based on the ob at 2 hours of post-operation, the parecoxib group showed a significantly lower level $(p<0.05)$ than the control group (Fig. 2).

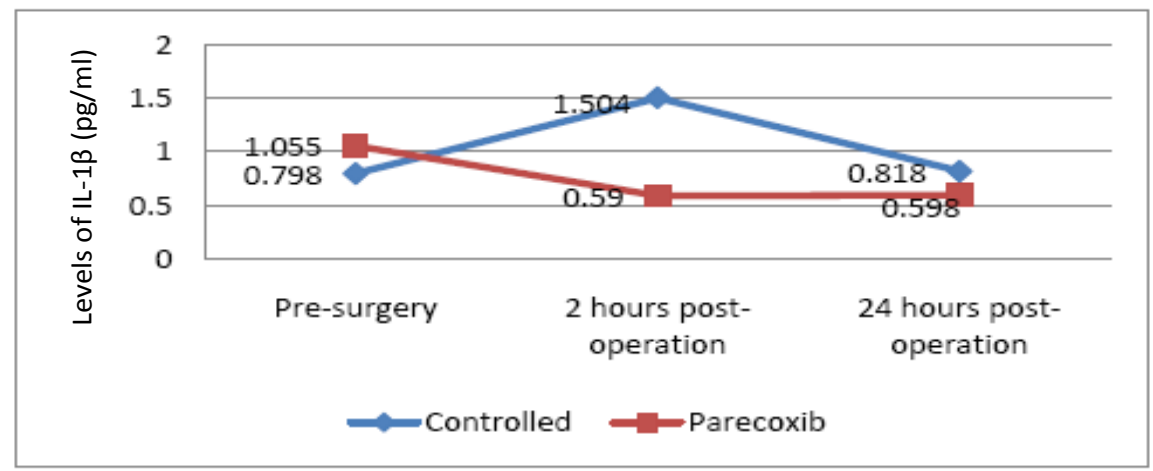

Fig. 1 Serum Interleukin -1ß Level 


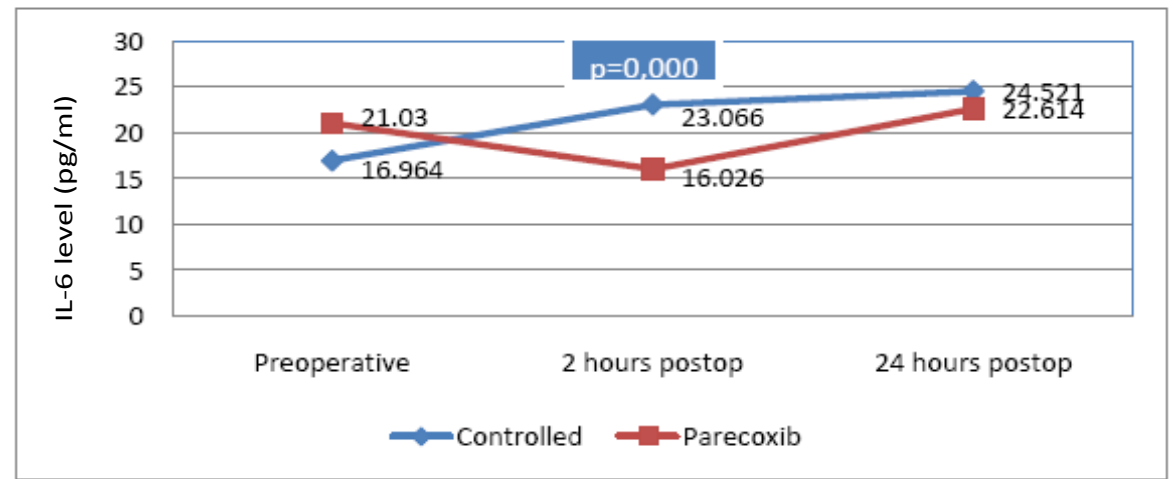

Fig. 2 Serum Interleukin-6 Level

Interleukin 10 level in both groups increased at two hours post-operation and no significant difference was found between the level in the parecoxib group $(4.46 \pm 3.51)$ and the control group (2.44 \pm 1.18$)$ ( $p=0.028$ ) (Fig. 3).

\section{Discussion}

Interleukin $-1 \beta$ level

Interleukin-1 $\beta$, which is a protein precursor, is produced by the macrophages and monocytes, known as non-immune cells, that is activated by fibroblast and endothelial cell during the occurence of tissue damage, infection, invasion and inflammation. It is now found that IL-1 $\beta$ also appears on nociceptive neurons in the dorsal root ganglion. Interleukin-1 $\beta$ contributes to the systemic inflammation through COX-2 activation to form PGE2. The result of this study shows that the IL-1 $\beta$ level in the parecoxib group decreased at 2 hours post-operation $(p<0.05)$, which is significantly different from the control group. However, 24 hours after operation, the IL-1 $\beta$ level in both groups decreased.

Another study combining spinal anesthesia and rofecoxib shows that the IL-1 $\beta$ level was undetected in plasma and LCS at 1, 3, 9, and 24 hours after surgery, and was only found in fluid from the drain of the surgery side. ${ }^{8}$

A study on ophthalmological surgery shows that there was no significant difference $(p>0.05)$ in IL-1 $\beta$ level between groups with parecoxib and without parecoxib. ${ }^{9}$ In that particular study, the IL-1 $\beta$ level showed a tendency to incline in both groups, with the parecoxib group showing less increase.

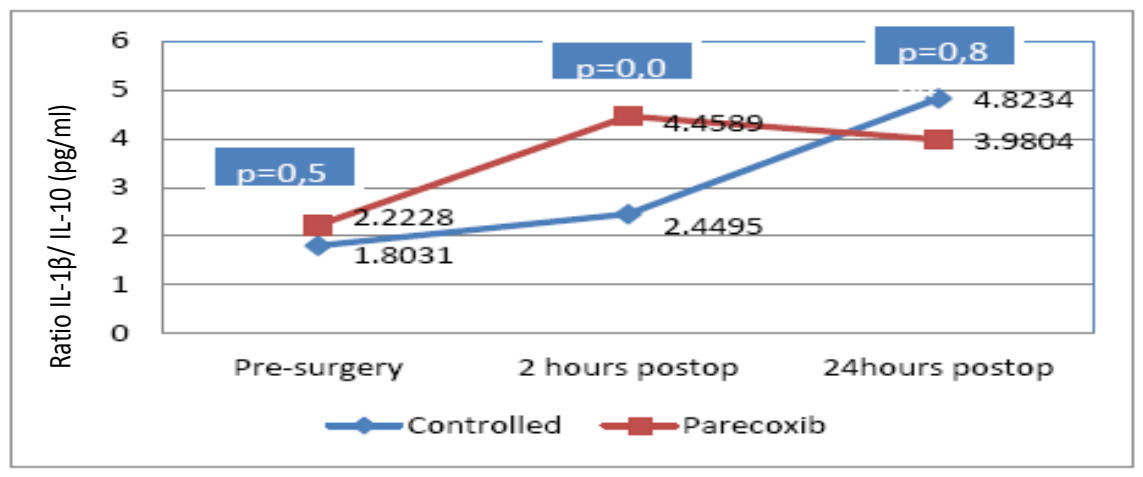

Fig. 3 Serum IL-10 Level 
Interleukin-6 Level

Surgical procedures are associated with tissue damages that activate both local and systemic nociceptive and inflammatory responses. This is then followed by proinflammatory cytokine increases, including the IL-6. ${ }^{8}$ The Interleukin-6 as the proinflammatory cytokine plays major roles in the acute protein phase of the tissue damages resulting from surgical trauma. From all body responses to surgical trauma, the IL- 6 level is reported to be the sensitive indicator of surgical stress. The Interleukin-6 concentration in a normal condition is usually low and may not be detected. ${ }^{10}$ After a trauma, the plasma IL-6 concentration can be detected in 60 minutes and will reach its peak after 4-6 hours. It starts to decrease between 24-48 hours after the trauma; however, it can persist until 10 days. Interleukin-6 is the most sensitive marker of tissue damages. The longer the IL-6 persists in the plasma, the higher the post-operative morbidity will be. ${ }^{13}$

The results of control group in this study are in agreement with the theories about IL-6. It is found that the IL-6 level increased at the $2^{\text {nd }}$ and $24^{\text {th }}$ hour after surgery $(p<0.05)$.

This finding is in line with the findings in a study performed on patients who underwent a transabdominal hysterectomy procedure using epidural analgesia preemptive technique, which was followed by Patient Controlled Epidural Analgesia (PCEA), where the IL-6 level increased in the first 24 hours post-operation $(p<0.03)$ but it was lower than PCEA group $(p<0.04) .{ }^{6}$

The IL- 6 dynamic in the control group is in line with the IL-6 serum level dynamic in a study on patients who underwent lower extremity surgical operation with epidural preemptive technique. ${ }^{11}$ Interleukin-6 will directly and indirectly affect the production of COX-2 and prostaglandin through IL-1. It is presumed that IL-6 can also activate the glia cell. ${ }^{13}$

It is stated that two pathways may be induced by peripheral inflammation. First, it induces the production and spread of COX2 and Prostaglandin E synthase (PGES) at the inflammation site, leading to the sensitization of nerves innervating the injured tissue by reducing their threshold and increasing their excitability. Second, the humoral pathway will be induced by the peripheral inflammation and this will increase the production and spread of COX-2 in CNS through NF-k $\beta$ by IL- $1 \beta$, TNF- $\alpha$, and IL- $6 .{ }^{7}$

The results of this study show that the IL-6 level in the parecoxib group decreased 2 hours after the surgery when it is compared to the presurgical value $(p<0.05)$ and it increased again at 24 hours after surgery $(p<0.05)$. In the control group, the IL-6 level keeps increasing during 24 hours after the surgery. There is a statistically significant difference of IL-6 level in both groups, particularly at two hours after the surgery $(p<0.05)$. No significant difference in IL-6 level between both groups before the surgery and 24 hours after surgery ( $p>0.05)$. These findings are presumably resulted from the inhibition of prostaglandin synthesis by parecoxib, which in turn affects the IL- 6 production.

The Interleukin- 6 production is initiated by the PGE2 receptor agonists. E-series prostaglandin receptors (EP) are the stimulated EP1 which enhances mobilization of calcium ( $\mathrm{Ca}$ ) from extracellular to intracellular compartment, while EP2 and EP4 receptors as G-protein-coupled receptors activate the cAMP and NF-k $\beta$ level. ${ }^{14}$

Recently, it is discovered that inflammation responses caused by surgical trauma cannot be

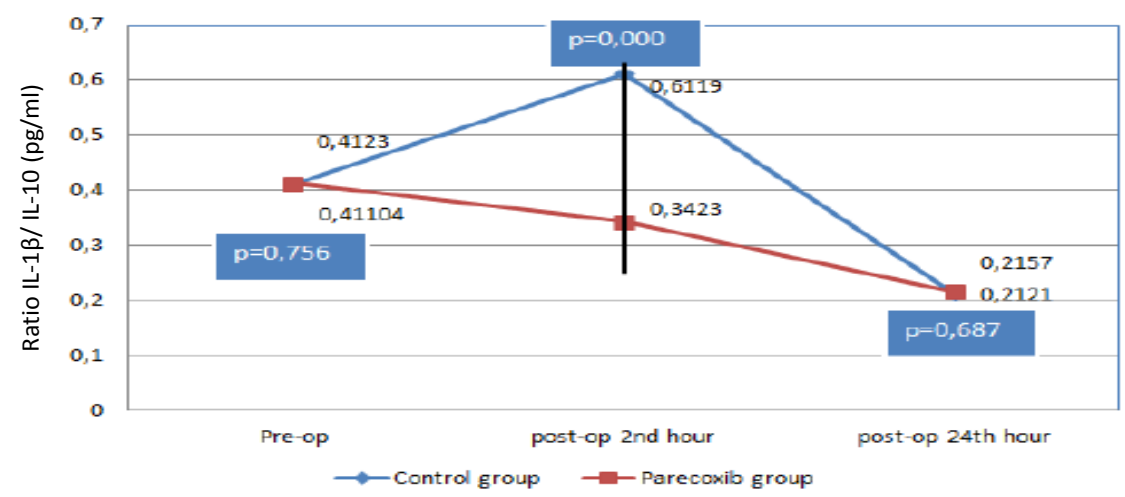

Fig. 4 Ratio IL1 $\beta /$ IL-10 


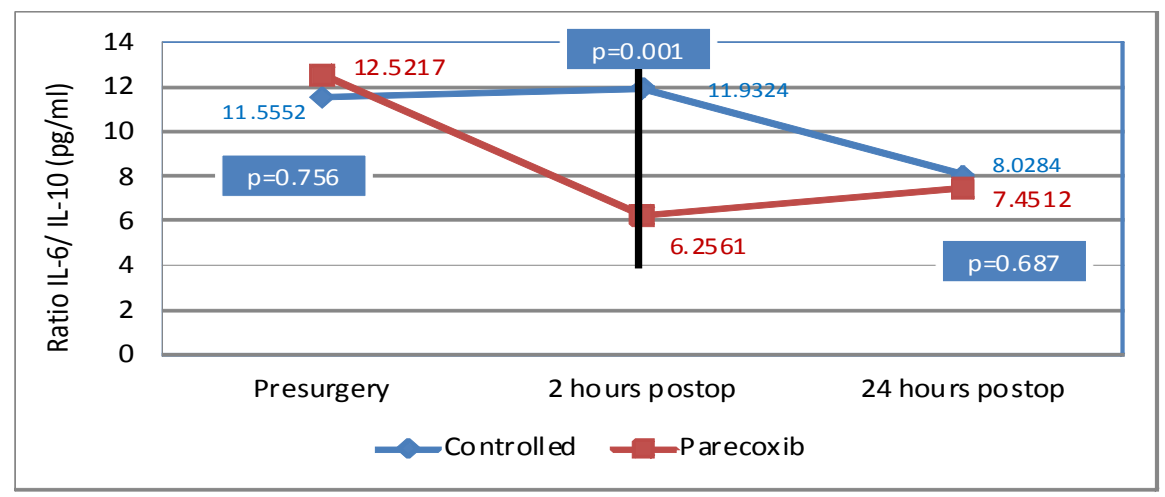

Fig. 5 Ratio IL-6 to IL-10

effectively inhibited merely by peripheral nerve inhibition or single neuraxial block. Peripheral inflammation induces COX-2 spread and PGES expression in CNS. Studies on animal subjects found that the proinflammatory cytokine, IL-6, induces COX-2, both in the inflamed peripheral tissue and CNS. In postoperative pain, IL-6 is known as a major mediator that increases the COX-2 in the CNS. New evidence has shown that parecoxib administration works centrally by inhibiting the COX-2; therefore, decreasing the expression of PGE2. This is different from ketorolac since this agent inhibits the COX-2 peripherally. ${ }^{15}$

The results of this study support the findings in a study on preemptive analgesia that used $40 \mathrm{mg}$ parecoxib adminitered intramuscularly before an ophthalmological surgery was performed under general anesthesia. ${ }^{9}$ It has been proven that the IL-6 plasma level in early post-operation until 6 hours post-surgery decreases $(p<0.05)$ compared to the control group but the difference of IL- 6 level at 24 hours after surgery is not significant compared to the control group. ${ }^{9}$

Based on a previous study that used oral preemptive COX-2 inhibitor combined with spinal anesthesia in arthroplasty, it is found that the IL-6 plasma experienced dynamic increases at the first 1, 3, 9, and 24 hours, and then decreases at 30 hours post-operation $(p<0.05)$. Overall, the IL-6 level is lower than in the control group. This study is also supported with the measurement of PGE2 plasma level, which decreases at all times of the postoperative assessment $(p<0.05){ }^{8}$

The results of this study contradicts findings from a previous study that involved the use of IV COX-2 inhibitor in thoracotomy patients. In that study, the IL- 6 level in both study groups increased until 24 hours after the surgery and decreased after that point. However, the IL-6 level in the treatment group was lower than in the control group $(p<0.05) .{ }^{10}$

Differences of IL-6 dynamic in those studies may be caused by the use of different types of COX-2 inhibitors. The similarity found among these studies is that in the group receiving COX-2 inhibitor, the IL- 6 level is found to be lower than in the control group, although the IL- 6 increases at the first 24 hours after surgery. These findings show that the administration of COX-2 inhibitor has an effect on the IL- 6 dynamic and level.

Therefore, a suggestion is proposed that the administration of $40 \mathrm{mg}$ IV parecoxib 30 minutes before a surgical incision can reduce and stabilize the IL-6 level. From this, we can conclude that parecoxib affects the dynamic of IL-6.

\section{Interleukin-10 Level}

The involvement of IL-10 in pain is thought to be through the effect on PGE2. The Interleukin 10 can inhibit the production of prostaglandin (PG) from peripheral blood mononuclear cells which is stimulated by the proinflammation cytokine. Anti-inflammatory cytokine increases after a trauma to maintain the balance between the anti-inflammation cytokine and the proinflammatory cytokines. The Interleukin 10 also inhibits the production of PG through a feedback mechanism. ${ }^{17}$ Results of this study show that the level of IL-10 increases in both groups and the difference is not significant. This shows that epidural analgesia, with or without parecoxib, causes an anti-inflammatory action through IL-10 response. This study is in line with 
another study that found IL-10 level increase after parecoxib administration. ${ }^{17}$

Proinflammatory to anti-inflammatory cytokines ratio

The balance between proinflammatory and anti-inflammatory cytokines are very important to maintain the homeostasis. In this study, the parecoxib group has lower IL-6/IL-10 and the IL$1 \beta / I L-10$ ratios at the $2^{\text {nd }}$ hour post-operation compared to control group. This shows that the administration of parecoxib has an effect on the systemic immune response. Peak levels of antiinflammatory cytokine IL-10 occurs two hours after the surgery and is higher in the parecoxib group. An increase in the ratio of IL-6 to IL-10 indicates a correlation with a poor outcome. This study has in line with the previous study. ${ }^{18}$ A different result is shown in an animal study in which the IL-6 and IL-10 levels decreases after parecoxib administration with poor outcome.

Multimodal Analgesia

The multimodal analgesia concept has been introduced more than a decade ago as a technique to increase the effect of analgesia and decrease unexpected incidences related to

\section{References}

1. Apfelbaum JL, Chen C, Mehta SS, Gan TJ. Postoperatif pain experience: result from a national survey suggest postoperatif continues to be undermanage. Anesth Analg. 2003;97(2):534-40.

2. Sommers M, Rijkea JM, Kleefa M, Kesselsa $\mathrm{AGH}$, Petersa ML, Geurtsa J, et al. The prevalence of postoperative pain in a sample of 1490 surgical inpatients. Eur J Anaesthesiol. 2008;25(04):267-74.

3. Buvanendran A, Kroin JS. Multimodal analgesia for controlling acute postoperative pain. Curr Opin Anaesthesiol. 2009;22:588-93.

4. Mahdy AM, Galley HF, Abdel-Wahed MA, El-Korny KF, Sheta SA, Webster NR. Differential modulation of interleukin- 6 and interleukin-10 by diclofenac in patient undergoing major surgery. $\mathrm{Br} \mathrm{J}$ Anesth. 2002;88(6):797-802.

5. Almaida JLJd, Jukemura J, Coelho AMM, Patzina RA, Machado MCC, Cunha JEMd. Inhibition of cyclooxygenase-2 in experimental severe acute pancreatitis. Clinics. 2006;6(4):301-6.

6. Beilin B, Bessler H, Mayburd E, Smirnov G, Dekel $A$, Yerdeni I, et al. Effect of preemtive analgesia the use of opioid. The rationale for this strategy is the achievement of sufficient analgesia due to the additive or synergistic effects between different classes of analgesics. ${ }^{3}$ This method can decrease the dosage of each individual drug, thus decreasing the adverse effects from each drug used in surgical procedure. Nowadays, the American Society of Anesthesiologist Task Force on Acute Pain Management suggested the use of this multimodal analgesia. ${ }^{3,18,19}$

The use of multimodal analgesia technique aims to decrease the stress response caused by surgical operations, reduce the mobility pain, ease the body recovery after surgery and increase the clinical improvement as well as decreasing the side effects of medications. ${ }^{20}$

In conclusion, the combination of $40 \mathrm{mg}$ of IV parecoxib and $0.125 \%$ bupivacaine epidural analgesia can change and stabilize the systemic immune response. This combination technique can also be used as a preventive multimodal analgesia to prevent chronic pains. Further studies are needed to measure the change in prostaglandin level as a direct effect from COX2 inhibitor and also to observe patients' clinical outcome. on pain and cytokine production in postoperative period. Am Societ Anesth. 2003;98(1):151-5.

7. Kawasaki T, Ogata M, Kawasaki CK, Okamoto, Sata T. Effects of epidural anaesthesia on surgical stress-induced immunosuppression during upper abdominal surgery. Br J Anaesth. 2007;98(2):196203.

8. Buvanandran A, Kroin J, Berger R, Hallab N, Saha C, Negrescu C, et al. Upregulated of prostaglandin $\mathrm{E} 2$ and interleukins in the central nervous system and peripheral tissue during and after surgery in humans. Anesthesiology. 2006;104(3):403-10.

9. Xu LL, Shen JJ, Zhou HY. Effects of parecoxib sodium preemtive analgesia on perioperative cytokine responses and stress responses in patients undergoing opthalmology surgery. Chin J Med Gen. 2010;90(27):1893-6.

10. Esme H, Kesli R, Apliogullari B, Duran FM, Yoldas B. Effect of flurbiprofen on CRP, TNF- $\alpha$, IL-6, and postoperative pain of thoracotomy. Int J Med Sci. 2011;8(3):816-221.

11. Ahmad MR. Peran analgesia epidural preemtif terhadap intensitas nyeri, respon hemodinamik serta dinamika kadar sitokin proinflamasi dan 
antiinflamasi pada pasca bedah ekstremitas bawah [desertation]. Makassar: Universitas Hasanuddin; 2012.

12. Beillin $Y$, Hossain $S$, Bodian $C A$. Numeric rating scale and labor epidural analgesia. Anesth Analg. 2003;109(3):943-50.

13. Jun-hua $Z$, Yu-guang $H$. Immune system: a new look at pain. Chin Med J. 2006;119(11):930-8.

14. Hamza M, Dionne RA. Mechanisms of non-opioid analgesics beyond cyclooxygenase enzyme inhibition. Curr Mol Pharm. 2009;2(1):1-14.

15. Katz J, Clarke H. Preventive analgesia and beyond: current status. evidence, and future directions. In: Rice AS, Justins D, Newton T, Howard RF, Miaskowski CA, editors. Clinical pain management. $2^{\text {nd }}$ ed. London: Hodder Arnold; 2008. p. 154-91.

16. Kim MH, Hahm TS. Plasma levels of Interleukin-6 and Interleukin-10 are affected by ketorolac as an adjunct to patient-controlled morphine after abdominal hysterectomy. Clin J Pain.
2001;17(1):72-7.

17. Wu Q, Purusram G, Wang H, Yuan R, Xie W, Gui $P$, et al. Effecacy of parecoxib on systemic inflammatory response assosiated with cardiopulmonary bypass during cardiac surgery. Br J Clin Pharmacol. 2013;75(3):769-78.

18. White PF, Sacan O, Tufanogullari B, Eng $M$, Nuangchamnong N, Ogunnaike B. Effect of short term postoperative celecoxib administration on patient outcome after outpatient laparascopic surgery. Can J Anaesth. 2007;54(5):342-8.

19. Fitzerald GA, Patrono C. Coxib, selective inhibitors of ciclooxygenase-2. N Eng J Med. 2001;345(6):433-42.

20. Reuben S, Buvanendran A. The role of preventive multimodal analgesia and impact on patient outcome. In: Sinatra RS, Leon-Casasola OAd, Ginsberg B, Viscusi ER, McQuay H, editors. Acute pain management. $1^{\text {st }}$ ed. New York: Cambridge University Press; 2009. p. 172-83. 